Brief communication

\title{
Analysis of the hexanucleotide repeat expansion and founder haplotype at C9ORF72 in an Irish psychosis case-control sample
}

\author{
Ciara Fahey $^{\mathrm{a}}$, Susan Byrne ${ }^{\mathrm{b}, \mathrm{c}}$, Russell McLaughlin ${ }^{\mathrm{d}}$, Kevin Kenna ${ }^{\mathrm{d}}$, Aleksey Shatunov ${ }^{\mathrm{e}, \mathrm{f}}$, \\ Gary Donohoe ${ }^{\mathrm{a}, \mathrm{c}}$, Michael Gill ${ }^{\mathrm{a}, \mathrm{c}}$, Ammar Al-Chalabi ${ }^{\mathrm{e}, \mathrm{f}}$, Daniel G. Bradley ${ }^{\mathrm{d}}$, \\ Orla Hardiman ${ }^{\mathrm{b}, \mathrm{c}}$, Aiden P. Corvin ${ }^{\mathrm{a}, \mathrm{c}}$, Derek W. Morris ${ }^{\mathrm{a}, \mathrm{c}, *}$ \\ ${ }^{a}$ Neuropsychiatric Genetics Research Group, Department of Psychiatry and Institute of Molecular Medicine, Trinity College Dublin, Dublin, Ireland \\ ${ }^{\mathrm{b}}$ Department of Neurology, Beaumont Hospital, Dublin, Ireland \\ ${ }^{\mathrm{c}}$ Trinity College Institute of Neuroscience, Trinity College Dublin, Dublin, Ireland \\ d Smurfit Institute of Genetics, Trinity College Dublin, Dublin, Ireland \\ e Medical Research Council Centre for Neurodegeneration Research, King's College London, London, UK \\ ${ }^{\mathrm{f}}$ Department of Clinical Neuroscience, Institute of Psychiatry, King's College London, London, UK
}

\section{A R T I C L E I N F O}

\section{Article history:}

Received 17 September 2013

Received in revised form 2 December 2013

Accepted 5 December 2013

\section{Keywords:}

C9ORF72

Association

Schizophrenia

Psychosis

Founder haplotype

\begin{abstract}
A B S T R A C T
The hexonucleotide repeat expansion 'GGGGCC' at the C9ORF72 gene has been strongly linked with amyotrophic lateral sclerosis and frontotemporal dementia. There is some evidence for clinical and genetic overlap between frontotemporal dementia and schizophrenia. Here, we genotyped the repeat at C9ORF72 in a large Irish psychosis case-control sample $(\mathrm{n}=2477)$. We found no carriers of $>30$ repeats. We found 7 samples with $>22$ repeats, 2 schizophrenia cases and 5 controls, but overall we observed no difference in the distribution of the repeat between our case and control samples. By using genome-wide association data to phase haplotypes at this gene, we investigated if carriers of the repeat expansion arose from a single common founder. All samples that carry 17 or more repeats also carry the founder haplotype and overall there is a very strong correlation between repeat length and the founder haplotype (Spearman rho $=0.714, p<0.001$ ). Our study provides further evidence to bolster the claim that carriers of the repeat expansion at C9ORF72 arose from a single common founder.
\end{abstract}

(c) 2014 Elsevier Inc. All rights reserved.

\section{Introduction}

A hexanucleotide repeat expansion 'GGGGCC' in the intronic region between exon $1 \mathrm{a}$ and exon $1 \mathrm{~b}$ of the C9ORF72 gene has been found to be associated with amyotrophic lateral sclerosis (ALS), frontotemporal dementia (FTD), and ALS comorbid with FTD (DeJesus-Hernandez et al., 2011; Renton et al., 2011). A previous study by members of our group found this expansion mutation in $41 \%$ of Irish familial ALS cases and in $5 \%$ of sporadic ALS cases (Byrne et al., 2012). These findings are representative of data reported across different geographical locations, for example, the expansion mutation was found in $39.3 \%$ of familial ALS cases and in $7 \%$ of sporadic ALS cases from the USA, Europe, and Australia (Majounie et al., 2012). The function of the C9ORF72 protein is

\footnotetext{
* Corresponding author at: Institute of Molecular Medicine, St. James' Hospital, Dublin 8, Ireland. Tel.: +3531 896 2424; fax: +35318963405.

E-mail address: derek.morris@tcd.ie (D.W. Morris).
}

unknown, but the repeat expansion is thought to reduce expression, in turn leading to disease through haploinsufficiency (Renton et al., 2011), and nuclear foci containing the expanded repeat in RNA transcripts have been found in spinal cord neurons of ALS patients (DeJesus-Hernandez et al., 2011). The repeat sequence is generally reported to be pathogenic when $>30$ repeats are present and the number of repeats can range from 700-1600 copies in FTD and/or ALS sufferers (Renton et al., 2011). The repeat range in the unaffected population was initially reported to be not higher than 23 but repeat numbers $>30$ have since been reported for neurologically normal controls (Ferrari et al., 2012). Overall, the functional impact of repeats that range from 20-30 remains unclear and a reliable cutoff for the pathologic repeat number is yet to be determined (Xi et al., 2012).

The repeat expansion is believed to have arisen on a single founder haplotype. The first evidence of a founder haplotype was reported by Laaksovirta et al. (2010) who detected a very strong association between a 42-Single Nucleotide Polymorphism (SNP) haplotype and familial ALS sample at the chromosome 9p21 


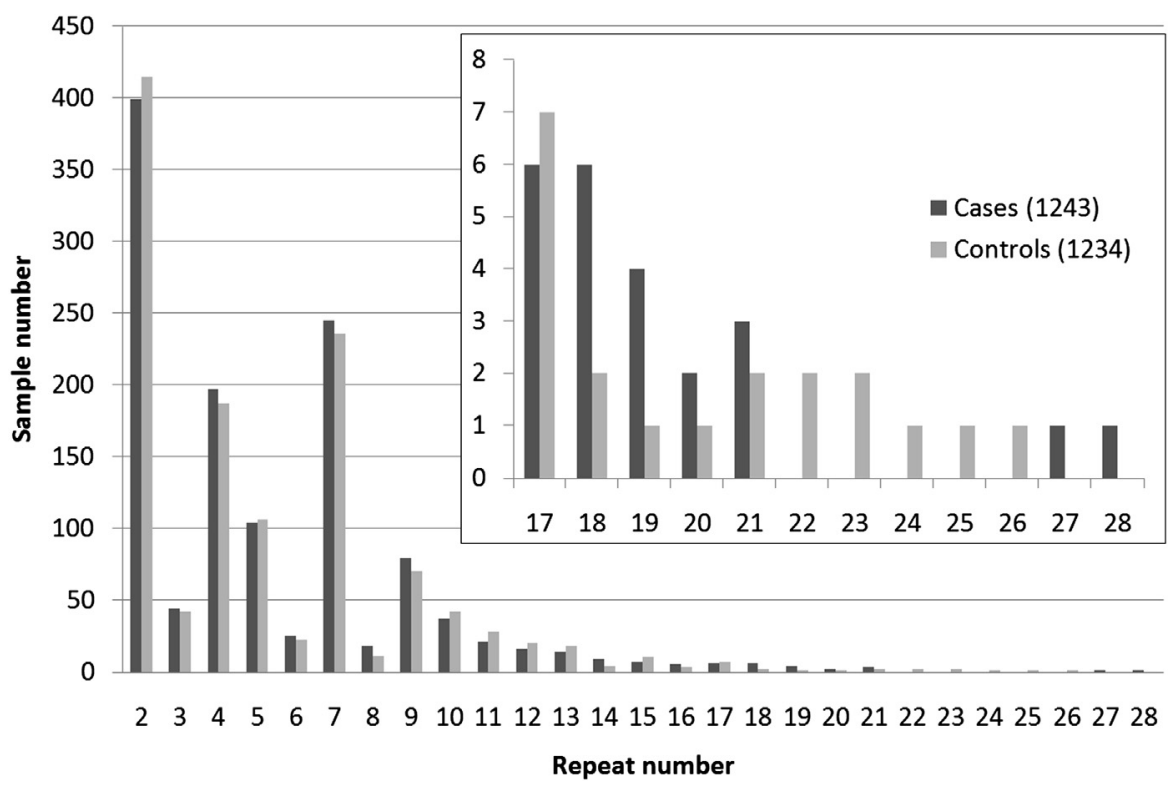

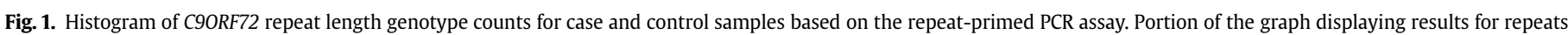
17-28 is magnified in upper right of graph. The data for this figure is provided in Supplementary Table S2. Abbreviation: PCR, polymerase chain reaction.

locus in a Finnish sample. In a subsequent study this haplotype was shortened to 20 SNPs over a 140-kb region (Mok et al., 2012). The most recent study by Smith et al. used next-generation sequencing to fine map the region and identify an 82-SNP founder haplotype (110 kb) spanning the C9ORF72 locus on which the expansion arose (Smith et al., 2013).

ALS and FTD are both progressive neurodegenerative disorders and are believed to be at two ends of a disease continuum (Fecto and Siddique, 2011; Lillo and Hodges, 2009). ALS is caused by degeneration of motor neurons, whereas FTD is a dementia caused by degeneration of neurons in the frontal and anterior temporal lobes leading to early behavioral and personality changes and language impairments. Clinical resemblance has been reported between frontal lobe syndrome and negative symptoms in schizophrenia (Stefansson et al., 2008; Ziauddeen et al., 2011), and people with younger onset FTD can be diagnosed with psychosis before being diagnosed with dementia (Velakoulis et al., 2009). Evidence for potential genetic overlap between FTD and schizophrenia has also been reported (Momeni et al., 2010; Schoder et al., 2010). In relation to C9ORF72, a high incidence of psychotic symptoms has been reported in FTD cases that carry the repeat expansion (Snowden et al., 2012). These data led Huey et al. to test for the C9ORF72 repeat expansion in a schizophrenia patient sample without FTD (Huey et al., 2013). No repeat expansions were detected in this relatively small sample $(\mathrm{n}=$ 192) but we now ask a similar question but in a much more powerful sample of 1271 Irish psychosis cases and 1283 controls. In addition, we use available genome-wide association study (GWAS) data to study the relationship between the founder haplotype and the repeat expansion in this large homogenous sample.

\section{Methods}

The total Irish case sample, which has been described as part of this study (Strange et al., 2012), numbered 1271 and included patients with a Diagnostic and Statistical Manual of Mental Disorders (DSM) IV diagnosis of schizophrenia $(\mathrm{n}=742)$, bipolar affective disorder I $(\mathrm{n}=261)$, schizoaffective disorder $(\mathrm{n}=162)$, and a smaller numbers of patients with major depressive disorder, delusional disorder samples or other psychotic illness $(n=106)$.
Twenty-eight case samples failed genotyping, giving a final number for analysis of 1243 . The Irish control sample $(n=1283)$ included 33 duplicate samples, which all produced identical genotypes to the original samples. Removal of these 33 samples plus 16 samples that failed genotyping left a final control sample for analysis of 1234 . Genotyping of the repeat was carried out using reverse primed polymerase chain reaction (Renton et al., 2011). All plates were run with 2 positive control DNA samples that have both previously been confirmed to contain $34+$ repeats. Seven samples had a number of repeats $>22$ and all were repeat-genotyped independently in King's College London, giving the same results. Both repeat genotype information and imputed GWAS data (Strange et al., 2012) were available for 779 cases and 815 controls. A set of 57 SNPs were extracted from the GWAS data that spanned the founder haplotype region at C9ORF72 (Smith et al., 2013) and these data were used to phase haplotypes using Plink (Purcell et al., 2007). The list of 57 SNPs is provided in Supplementary Table S1. More detailed methods are supplied in Supplementary Information.

\section{Results}

Of the 1243 case and 1234 control samples analyzed, none were found to have a hexanucleotide expansion with $>30$ repeats. We found 7 samples with $>22$ repeats (Fig. 1 and Supplementary Table S2). These included 2 schizophrenia case samples (with 28 and 27 repeats) and 5 control samples (with $23-26$ repeats). It is interesting that the 2 samples with the longest number of repeats are both case samples but overall there is no evidence of association between the repeat and schizophrenia using any definition of the pathologic repeat number between 20 and 30 .

From our imputed GWAS data at C9ORF72, we had genotype information for 57 of the 82 SNPs used by Smith et al. (2013) to define the founder haplotype that carries the repeat expansion. The SNPs that make up this haplotype are a collection of variants in high LD over a region of $95 \mathrm{~kb}$ that extends telomeric from intron 1 of the gene on the short arm of chromosome 9. This is not a continuous haplotype block as there are many SNPs within this region that are not in LD with the variants that contribute to the founder haplotype. Because of the high LD between SNPs, 
data from our 57 SNPs was sufficient to capture the founder haplotype, which has a frequency of 0.159 in our combined case and control sample. We were able to phase $64 \%$ of our sample for the founder haplotype with a post-probability of $>0.8$. We next plotted individual samples based on their repeat number and whether or not they carried the founder haplotype (Fig. 2 and Supplementary Table S3). We observe a very significant correlation between the founder haplotype and an extended repeat number (Spearman's Rho $=0.685, p<0.001$ ). We observed a small number of individual samples that had a long repeat number (e.g., $>16$ repeats) but did not carry the founder haplotype. Inspection of the haplotypes in these samples showed that they carried a haplotype that was near identical to the founder haplotype but differed because of a single base change (A to $C$ ) at rs10511816, the most telomeric SNP in the haplotype. Smith et al. also reported this version of the founder haplotype in their study. This haplotype has a frequency of 0.033 in our combined case and control sample. When we combined these two versions of the founder haplotype for analysis, the correlation coefficient between the repeat number and founder haplotype was even stronger (Spearman's Rho $=0.714, p<0.001$ ).

\section{Discussion}

The hexanucleotide repeat expansion 'GGGGCC' at the C9ORF72 gene has been strongly associated with ALS and FTD. There is some evidence for clinical and genetic overlap between FTD and schizophrenia. In a study of C9ORF72, the presence of psychosis in FTD patients dramatically increased the odds that these individuals carried the repeat expansion mutation (Snowden et al., 2012). A previous study reported no carriers of the pathogeniclength repeat expansion in small sample of 192 schizophrenia patients (Huey et al., 2013). Here, we genotyped the repeat expansion at C9ORF72 in a much larger Irish psychosis casecontrol sample. We found no carriers of $>30$ repeats, the putative start of the pathogenic range for this mutation. We found 7 samples with $>22$ repeats, 2 schizophrenia cases, and 5 controls. The case samples had the longest number of repeats in our samples (27 and 28 repeats), but overall we saw no difference in the distribution of the repeat between our case and control sample. Reports have shown a high level of intermediate copy numbers $(>20-30+)$ in a number of Parkinson's disease patients (Nuytemans et al., 2013) and intermediate-sized repeats have also been linked to cases of ALS (Byrne et al., 2013) and FTD (GomezTortosa et al., 2013). The functional impact and importance of the repeat at different lengths remains to be elucidated. In our control sample, $0.8 \%$ of individuals carried 20 or more repeats, whereas in a similar study carried out in the UK population, the C9ORF72 repeat expansion was seen in $0.15 \%$ of the control population (Beck et al., 2013).

We used available GWAS data for our sample to investigate the founder haplotype on which this repeat expansion is reported to have arisen (Smith et al., 2013). Our data supports the claim that carriers of the expansion arose from a single common founder, or at the very least that if the expansion arose multiple times, it has done so on the same haplotype background. In the Irish population, two versions of the founder haplotype are evident and are differentiated from each other by the SNP rs10511816. Based on our data, the frequency of the founder haplotype in the Irish population is 0.192 . All samples that carry 17 or more repeats also carry a version of the founder haplotype and overall there is a very strong correlation between repeat length and the founder haplotype. Of the 621 samples carrying $>6$ repeats, $78 \%$ carry the founder haplotype. The largest number of repeats carried by an individual sample that does not carry a copy of the founder haplotype is 16 repeats. The founder haplotype is only detected in $3 \%$ of 973 samples that have between 2 and 6 repeats.

In summary, we find no strong evidence to support a role for the repeat expansion at C9ORF72 in psychosis. Greater understanding of the functional impact of repeat lengths $<30$ may help in the interpretation of our data. We do present further strong support to back the claim that this repeat arose in a single common founder.

\section{Disclosure statement}

The authors have no actual or potential conflicts of interest.

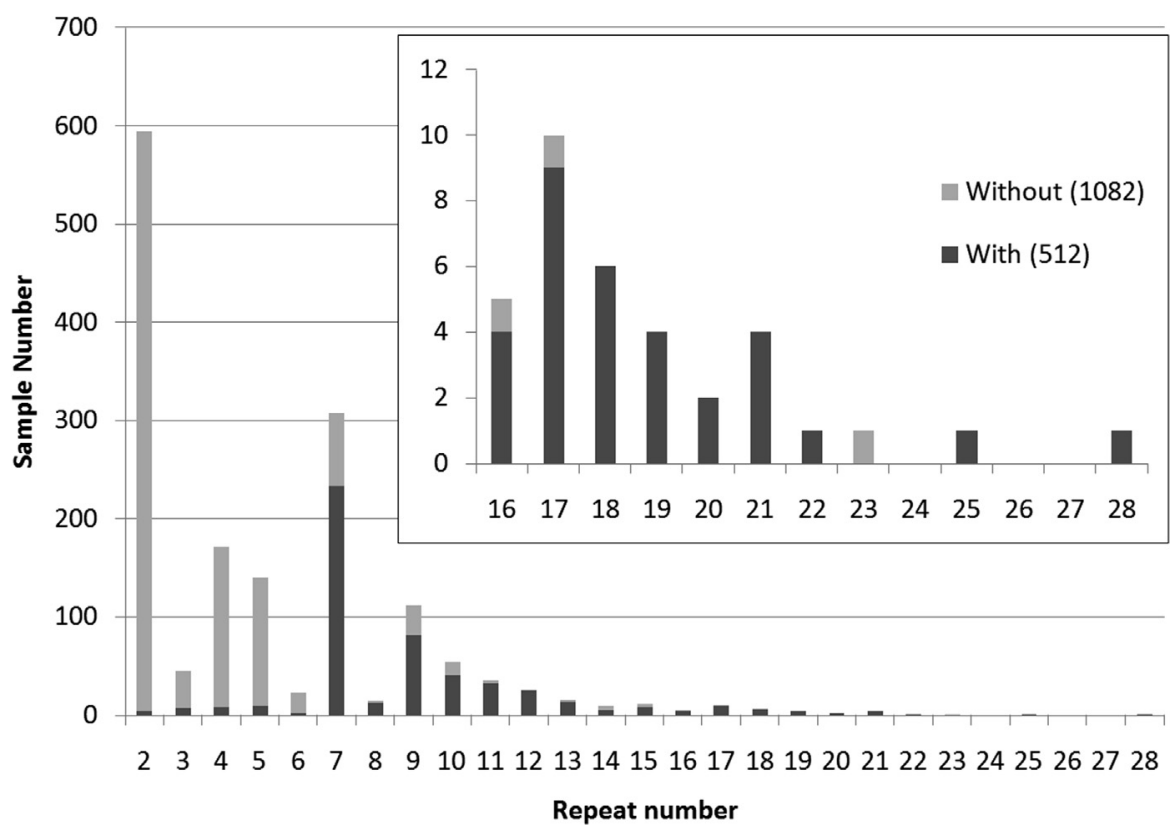

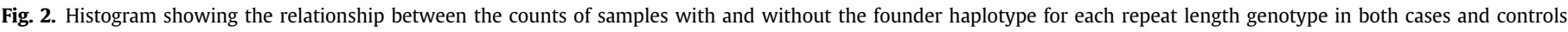
combined. Portion of the graph displaying results for repeats $16-28$ is magnified in upper right of graph. The data for this figure is provided in Supplementary Table S3. 


\section{Acknowledgements}

The authors sincerely thank all patients who contributed to this study and all staff who facilitated their involvement. Funding for this study was provided by Science Foundation Ireland (08/IN.1/ B1916). The authors acknowledge the Wellcome Trust Case Control Consortium 2 project for the GWAS data used in the founder haplotype analysis. The authors acknowledge use of the Trinity Biobank Irish control sample and the support of the Trinity Centre for High Performance Computing. Thanks to S. Kelly for assistance with statistical analysis.

\section{Appendix A. Supplementary data}

Supplementary data associated with this article can be found, in the online version, at http://dx.doi.org/10.1016/j.neurobiolaging. 2013.12.003.

\section{References}

Beck, J., Poulter, M., Hensman, D., Rohrer, J.D., Mahoney, C.J., Adamson, G., Campbell, T., Uphill, J., Borg, A., Fratta, P., Orrell, R.W., Malaspina, A., Rowe, J., Brown, J., Hodges, J., Sidle, K., Polke, J.M., Houlden, H., Schott, J.M., Fox, N.C., Rossor, M.N., Tabrizi, S.J., Isaacs, A.M., Hardy, J., Warren, J.D., Collinge, J., Mead, S., 2013. Large C9orf72 hexanucleotide repeat expansions are seen in multiple neurodegenerative syndromes and are more frequent than expected in the UK population. Am. J. Hum. Genet. 92, 345-353.

Byrne, S., Elamin, M., Bede, P., Shatunov, A., Walsh, C., Corr, B., Heverin, M., Jordan, N., Kenna, K., Lynch, C., McLaughlin, R.L., Iyer, P.M., O’Brien, C., Phukan, J., Wynne, B., Bokde, A.L., Bradley, D.G., Pender, N., Al-Chalabi, A., Hardiman, O., 2012. Cognitive and clinical characteristics of patients with amyotrophic lateral sclerosis carrying a C9orf72 repeat expansion: a population-based cohort study. Lancet Neurol. 11, 232-240.

Byrne, S., Heverin, M., Elamin, M., Walsh, C., Hardiman, O., 2013. Intermediate repeat expansion length in C9orf72 may be pathological in amyotrophic lateral sclerosis. Amyotroph. Lateral Scler. Frontotemporal Degener [Epub ahead of print].

Dejesus-Hernandez, M., Mackenzie, I.R., Boeve, B.F., Boxer, A.L., Baker, M., Rutherford, N.J., Nicholson, A.M., Finch, N.A., Flynn, H., Adamson, J., Kouri, N., Wojtas, A., Sengdy, P., Hsiung, G.Y., Karydas, A., Seeley, W.W., Josephs, K.A., Coppola, G., Geschwind, D.H., Wszolek, Z.K., Feldman, H., Knopman, D.S., Petersen, R.C., Miller, B.L., Dickson, D.W., Boylan, K.B., Graff-Radford, N.R., Rademakers, R., 2011. Expanded GGGGCC hexanucleotide repeat in noncoding region of C9orf72 causes chromosome 9p-Linked FTD and ALS. Neuron 72, 245-256.

Fecto, F., Siddique, T., 2011. Making connections: pathology and genetics link amyotrophic lateral sclerosis with frontotemporal lobe dementia. J. Mol. Neurosci. 45, 663-675.

Ferrari, R., Mok, K., Moreno, J.H., Cosentino, S., Goldman, J., Pietrini, P., Mayeux, R., Tierney, M.C., Kapogiannis, D., Jicha, G.A., Murrell, J.R., Ghetti, B., Wassermann, E.M., Grafman, J., Hardy, J., Huey, E.D., Momeni, P., 2012. Screening for C9orf72 repeat expansion in FTLD. Neurobiol. Aging 33, 1850.e1-1850.e11.

Gomez-Tortosa, E., Gallego, J., Guerrero-Lopez, R., Marcos, A., Gil-Neciga, E., Sainz, M.J., Diaz, A., Franco-Macias, E., Trujillo-Tiebas, M.J., Ayuso, C., PerezPerez, J., 2013. C9orf72 hexanucleotide expansions of 20-22 repeats are associated with frontotemporal deterioration. Neurology 80, 366-370.

Huey, E.D., Nagy, P.L., Rodriguez-Murillo, L., Manoochehri, M., Goldman, J., Lieberman, J., Karayiorgou, M., Mayeux, R., 2013. C9orf72 repeat expansions not detected in a group of patients with schizophrenia. Neurobiol. Aging 34, 1309.e9-1309.e10.

Laaksovirta, H., Peuralinna, T., Schymick, J.C., Scholz, S.W., Lai, S.L., Myllykangas, L. Sulkava, R. Jansson, L., Hernandez, D.G., Gibbs, J.R., Nalls, M.A., Heckerman, D., Tienari, P.J., Traynor, B.J., 2010. Chromosome 9p21 in amyotrophic lateral sclerosis in Finland: a genome-wide association study. Lancet Neurol. 9, 978-985.

Lillo, P., Hodges, J.R., 2009. Frontotemporal dementia and motor neuron disease: overlapping clinic-pathological disorders. J. Clin. Neurosci. 16, 1131-1135.

Majounie, E., Renton, A.E., Mok, K., Dopper, E.G., Waite, A., Rollinson, S., Chiò, A., Restagno, G., Nicolaou, N., Simon-Sanchez, J., van Swieten, J.C., Abramzon, Y., Johnson, J.O., Sendtner, M., Pamphlett, R., Orrell, R.W., Mead, S., Sidle, K.C., Houlden, H., Rohrer, J.D., Morrison, K.E., Pall, H., Talbot, K., Ansorge, O., Chromosome 9-ALS/FTD ConsortiumFrench research network on FTLD/FTLD/ALSITALSGEN Consortium, Hernandez, D.G., Arepalli, S., Sabatelli, M., Mora, G., Corbo, M., Giannini, F., Calvo, A., Englund, E., Borghero, G., Floris, G.L., Remes, A.M., Laaksovirta, H., McCluskey, L., Trojanowski, J.Q., Van Deerlin, V.M., Schellenberg, G.D., Nalls, M.A., Drory, V.E., Lu, C.S., Yeh, T.H., Ishiura, H., Takahashi, Y., Tsuji, S., Le Ber, I., Brice, A., Drepper, C., Williams, N., Kirby, J., Shaw, P., Hardy, J., Tienari, P.J., Heutink, P., Morris, H.R., Pickering-Brown, S., Traynor, B.J., 2012. Frequency of the C9orf72 hexanucleotide repeat expansion in patients with amyotrophic lateral sclerosis and frontotemporal dementia: a cross-sectional study. Lancet Neurol. 11, 323-330.

Mok, K., Traynor, B.J., Schymick, J., Tienari, P.J., Laaksovirta, H., Peuralinna, T. Myllykangas, L., Chiò, A., Shatunov, A., Boeve, B.F., Boxer, A.L., DeJesusHernandez, M., Mackenzie, I.R., Waite, A., Williams, N., Morris, H.R., SimónSánchez, J., van Swieten, J.C., Heutink, P., Restagno, G., Mora, G., Morrison, K.E., Shaw, P.J., Rollinson, P.S., Al-Chalabi, A., Rademakers, R., Pickering-Brown, S., Orrell, R.W., Nalls, M.A., Hardy, J., 2012. Chromosome 9 ALS and FTD locus is probably derived from a single founder. Neurobiol. Aging 33, 209.e3-209.e8.

Momeni, P., Wickremaratchi, M.M., Bell, J., Arnold, R., Beer, R., Hardy, J., Revesz, T., Neal, J.W., Morris, H.R., 2010. Familial early onset frontotemporal dementia caused by a novel S356T MAPT mutation, initially diagnosed as schizophrenia. Clin. Neurol. Neurosurg. 112, 917-920.

Nuytemans, K., Bademci, G., Kohli, M.M., Beecham, G.W., Wang, L., Young, J.I, Nahab, F., Martin, E.R., Gilbert, J.R., Benatar, M., Haines, J.L., Scott, W.K. Zuchner, S., Pericak-Vance, M.A., Vance, J.M., 2013. C9orf72 intermediate repeat copies are a significant risk factor for Parkinson disease. Ann. Hum. Genet. [Epub ahead of print].

Purcell, S., Neale, B., Todd-Brown, K., Thomas, L., Ferreira, M.A., Bender, D., Maller, J., Sklar, P., de Bakker, P.I., Daly, M.J., Sham, P.C., 2007. PLINK: a tool set for wholegenome association and population-based linkage analyses. Am. J. Hum. Genet. 81, 559-575.

Renton, A.E., Majounie, E., Waite, A., Simon-Sanchez, J., Rollinson, S., Gibbs, J.R. Schymick, J.C., Laaksovirta, H., van Swieten, J.C., Myllykangas, L., Kalimo, H. Paetau, A., Abramzon, Y., Remes, A.M., Kaganovich, A., Scholz, S.W. Duckworth, J., Ding, J., Harmer, D.W., Hernandez, D.G., Johnson, J.O., Mok, K. Ryten, M., Trabzuni, D., Guerreiro, R.J., Orrell, R.W., Neal, J., Murray, A., Pearson, J., Jansen, I.E., Sondervan, D., Seelaar, H., Blake, D., Young, K., Halliwell, N., Callister, J.B., Toulson, G., Richardson, A., Gerhard, A., Snowden, J. Mann, D., Neary, D., Nalls, M.A., Peuralinna, T., Jansson, L., Isoviita, V.M., Kaivorinne, A.L., Holtta-Vuori, M., Ikonen, E., Sulkava, R., Benatar, M., Wuu, J. Chio, A., Restagno, G., Borghero, G., Sabatelli, M., Heckerman, D., Rogaeva, E., Zinman, L., Rothstein, J.D., Sendtner, M., Drepper, C., Eichler, E.E., Alkan, C. Abdullaev, Z., Pack, S.D., Dutra, A., Pak, E., Hardy, J., Singleton, A., Williams, N.M., Heutink, P., Pickering-Brown, S., Morris, H.R., Tienari, P.J., Traynor, B.J., 2011. A hexanucleotide repeat expansion in C9orf72 is the cause of chromosome 9p21-linked ALS-FTD. Neuron 72, 257-268.

Schoder, D., Hannequin, D., Martinaud, O. Opolczynski, G, Guyant-Marechal, L, Le Ber, I., Campion, D., 2010. Morbid risk for schizophrenia in first-degree relatives of people with frontotemporal dementia. Br. J. Psychiatry 197, 28-35.

Smith, B.N., Newhouse, S., Shatunov, A., Vance, C., Topp, S., Johnson, L., Miller, J. Lee, Y., Troakes, C., Scott, K.M., Jones, A., Gray, I., Wright, J., Hortobagyi, T., Al-Sarraj, S., Rogelj, B., Powell, J., Lupton, M., Lovestone, S., Sapp, P.C., Weber, M. Nestor, P.J., Schelhaas, H.J., Asbroek, A.A., Silani, V., Gellera, C., Taroni, F., Ticozzi, N., Van den Berg, L., Veldink, J., Van Damme, P., Robberecht, W. Shaw, P.J., Kirby, J., Pall, H., Morrison, K.E., Morris, A., de Belleroche, J., Vianney de Jong, J.M., Baas, F., Andersen, P.M., Landers, J., Brown Jr., R.H., Weale, M.E., AlChalabi, A., Shaw, C.E., 2013. The C9orf72 expansion mutation is a common cause of ALS+/-FTD in Europe and has a single founder. Eur. J. Hum. Genet. 21, $102-108$.

Snowden, J.S., Rollinson, S., Thompson, J.C., Harris, J.M., Stopford, C.L., Richardson, A.M., Jones, M., Gerhard, A., Davidson, Y.S., Robinson, A., Gibbons, L., Hu, Q., DuPlessis, D., Neary, D., Mann, D.M., Pickering-Brown, S.M., 2012. Distinct clinical and pathological characteristics of frontotemporal dementia associated with C9orf72 mutations. Brain 135, 693-708.

Stefansson, H., Rujescu, D., Cichon, S., Pietilainen, O.P., Ingason, A., Steinberg, S. Fossdal, R., Sigurdsson, E., Sigmundsson, T., Buizer-Voskamp, J.E., Hansen, T. Jakobsen, K.D., Muglia, P., Francks, C., Matthews, P.M., Gylfason, A., Halldorsson, B.V., Gudbjartsson, D., Thorgeirsson, T.E., Sigurdsson, A., Jonasdottir, A., Bjornsson, A., Mattiasdottir, S., Blondal, T., Haraldsson, M. Magnusdottir, B.B., Giegling, I., Moller, H.J., Hartmann, A., Shianna, K.V., Ge, D. Need, A.C., Crombie, C., Fraser, G., Walker, N., Lonnqvist, J., Suvisaari, J., TuulioHenriksson, A., Paunio, T., Toulopoulou, T., Bramon, E., Di Forti, M., Murray, R. Ruggeri, M., Vassos, E., Tosato, S., Walshe, M., Li, T., Vasilescu, C. Muhleisen, T.W., Wang, A.G., Ullum, H., Djurovic, S., Melle, I., Olesen, J., Kiemeney, L.A., Franke, B., Sabatti, C., Freimer, N.B., Gulcher, J.R. Thorsteinsdottir, U., Kong, A., Andreassen, O.A., Ophoff, R.A., Georgi, A. Rietschel, M., Werge, T., Petursson, H., Goldstein, D.B., Nothen, M.M., Peltonen, L., Collier, D.A., St Clair, D., Stefansson, K., 2008. Large recurrent microdeletions associated with schizophrenia. Nature 455, 232-236.

Strange, A., Riley, B.P., Spencer, C.A., Morris, D.W., Pirinen, M., O’Dushlaine, C.T., Su, Z., Maher, B.S., Freeman, C., Cormican, P., Bellenguez, C., Kenny, E.M., Band, G., Wormley, B., Donohoe, G., Dilthey, A., Moutsianas, L., Quinn, E., Edkins, S., Judge, R., Coleman, K., Hunt, S., Tropea, D., Roche, S., Cummings, L., Kelleher, E., McKeon, P., Dinan, T., McDonald, C., Murphy, K.C., O’Callaghan, E., O'Neill, F.A., Waddington, J.L., Walsh, D. Giannoulatou, E., Langford, C. Deloukas, P., Gray, E., Dronov, S., Potter, S., Pearson, R., Vukcevic, D., TashakkoriGhanbaria, A., Blackwell, J.M., Bramon, E., Brown, M.A., Casas, J.P., Duncanson, A. Jankowski, J., Markus, H.S., Mathew, C.G., Palmer, C.N.A., Plomin, R.P., Rautanen, A., Sawcer, S.J., Trembath, R.C., Viswanathan, A.C., Wood, N.W. Stone, J., Scolnick, E., Purcell, S., Sklar, P., SGENE+ Consortium, Ripke, S. Walters, J., Owen, M.J., O’Donovan, M.C., Schizophrenia Working Group of the Psychiatric GWAS Consortium, Peltonen, L., McVean, G., Kendler, K.S., Gill, M., Donnelly, P., Corvin A for Irish Schizophrenia Genomics Consortium and the Wellcome Trust Case Control Consortium 2, 2012. Genome-wide association 
study implicates HLA-C*01:02 as a risk factor at the major histocompatibility complex locus in schizophrenia. Biol. Psychiatry 72, 620-628.

Velakoulis, D., Walterfang, M., Mocellin, R., Pantelis, C., McLean, C., 2009. Frontotemporal dementia presenting as schizophrenia-like psychosis in young people: clinicopathological series and review of cases. Br. J. Psychiatry 194, $298-305$.

Xi, Z., Zinman, L., Grinberg, Y., Moreno, D., Sato, C., Bilbao, J.M., Ghani, M., Hernandez, I., Ruiz, A., Boada, M., Moron, F.J., Lang, A.E., Marras, C., Bruni, A., Colao, R.,
Maletta, R.G., Puccio, G., Rainero, I., Pinessi, L., Galimberti, D., Morrison, K.E. Moorby, C., Stockton, J.D., Masellis, M., Black, S.E., Hazrati, L.N., Liang, Y., van Haersma de With, J., Fornazzari, L., Villagra, R., Rojas-Garcia, R., Clarimon, J., Mayeux, R., Robertson, J., St George-Hyslop, P., Rogaeva, E., 2012. Investigation of C9orf72 in 4 neurodegenerative disorders. Arch. Neurol. 69, 1583-1590. Ziauddeen, H., Dibben, C., Kipps, C., Hodges, J.R., McKenna, P.J., 2011. Negative schizophrenic symptoms and the frontal lobe syndrome: one and the same? Eur. Arch. Psychiatry Clin. Neurosci. 261, 59-67. 